\title{
Contribution of Cell Elongation to the Biofilm Formation of Pseudomonas aeruginosa during Anaerobic Respiration
}

\author{
Mi Young Yoon ${ }^{19}$, Kang-Mu Lee ${ }^{19}$, Yongjin Park ${ }^{1}$, Sang Sun Yoon ${ }^{1,2,3 *}$ \\ 1 Department of Microbiology, Yonsei University College of Medicine, Seoul, Republic of Korea, 2 Brain Korea 21 Project for Medical Sciences, Yonsei University College of \\ Medicine, Seoul, Republic of Korea, 3 Research Institute of Bacterial Resistance, Yonsei University College of Medicine, Seoul, Republic of Korea
}

\begin{abstract}
Pseudomonas aeruginosa, a gram-negative bacterium of clinical importance, forms more robust biofilm during anaerobic respiration, a mode of growth presumed to occur in abnormally thickened mucus layer lining the cystic fibrosis (CF) patient airway. However, molecular basis behind this anaerobiosis-triggered robust biofilm formation is not clearly defined yet. Here, we identified a morphological change naturally accompanied by anaerobic respiration in $P$. aeruginosa and investigated its effect on the biofilm formation in vitro. A standard laboratory strain, PAO1 was highly elongated during anaerobic respiration compared with bacteria grown aerobically. Microscopic analysis demonstrated that cell elongation likely occurred as a consequence of defective cell division. Cell elongation was dependent on the presence of nitrite reductase (NIR) that reduces nitrite $\left(\mathrm{NO}_{2}{ }^{-}\right)$to nitric oxide $(\mathrm{NO})$ and was repressed in PAO1 in the presence of carboxy-PTIO, a $\mathrm{NO}$ antagonist, demonstrating that cell elongation involves a process to respond to NO, a spontaneous byproduct of the anaerobic respiration. Importantly, the non-elongated NIR-deficient mutant failed to form biofilm, while a mutant of nitrate reductase (NAR) and wild type PAO1, both of which were highly elongated, formed robust biofilm. Taken together, our data reveal a role of previously undescribed cell biological event in P. aeruginosa biofilm formation and suggest NIR as a key player involved in such process.
\end{abstract}

Citation: Yoon MY, Lee K-M, Park Y, Yoon SS (2011) Contribution of Cell Elongation to the Biofilm Formation of Pseudomonas aeruginosa during Anaerobic Respiration. PLoS ONE 6(1): e16105. doi:10.1371/journal.pone.0016105

Editor: Deepak Kaushal, Tulane University, United States of America

Received August 26, 2010; Accepted December 7, 2010; Published January 18, 2011

Copyright: (c) 2011 Yoon et al. This is an open-access article distributed under the terms of the Creative Commons Attribution License, which permits unrestricted use, distribution, and reproduction in any medium, provided the original author and source are credited.

Funding: This work was supported by a grant of the Korea Healthcare Technology R\&D Project, Ministry for Health, Welfare and Family Affairs, Republic of Korea, A090951 to SSY. The funders had no role in study design, data collection and analysis, decision to publish, or preparation of the manuscript.

Competing Interests: The authors have declared that no competing interests exist.

* E-mail: sangsun_yoon@yuhs.ac

9 These authors contributed equally to this work.

\section{Introduction}

Pseudomonas aeruginosa propagates as complex, highly organized communities known as biofilms in the environment and during various infections [1]. Bacterial biofilms are the most common causes of chronic $P$. aeruginosa infection and are difficult to eradicate. For example, $P$. aeruginosa in biofilms have been reported to be more resistant to $\mathrm{H}_{2} \mathrm{O}_{2}$ [2], a range of antibiotics [3] and various heavy metals [4]. Moreover, bacteria grown as biofilms are more resistant to neutrophil-mediated host defenses than are their free-living planktonic counterparts [5].

$P$. aeruginosa can generate sufficient energy even under anaerobic conditions through respiration using nitrate $\left(\mathrm{NO}_{3}{ }^{-}\right)$or nitrite $\left(\mathrm{NO}_{2}{ }^{-}\right)$as terminal electron acceptors [6,7]. It was demonstrated that (i) the oxygen potential of abnormally altered CF airways, which are highly susceptible to chronic $P$. aeruginosa infection, is extremely low [8] and (ii) that nitrate $\left(\mathrm{NO}_{3}{ }^{-}\right)$and nitrite $\left(\mathrm{NO}_{2}{ }^{-}\right)$ are present in large quantities inside patient airways [9,10]. Given the fact that PAOl, when grown under anaerobic conditions, becomes more resistant to antibiotic treatment [11], these findings provided a novel insight that reflects $P$. aeruginosa infection dynamics in CF airways and suggested to change the way of confronting $P$. aeruginosa airway infection.
Genome-wide microarray analysis revealed that the expression of a total of 691 genes (12\% of the genome) was modulated upon anaerobic growth demonstrating that $P$. aeruginosa, as a versatile organism, can actively adapt itself to growth with alternative electron acceptors [12]. Cellular events that specifically occur during anaerobic respiration include decreased production of pyocyanin [13] and elastase [14], increased levels of alginate secretion [8], consistent production of sublethal levels of $\mathrm{NO}$ $[6,15,16]$ and enhanced biofilm formation $[17,18]$. Although the molecular basis of these anaerobiosis-induced changes is not fully understood, it is likely that $P$. aeruginosa may increase its survival fitness inside the patient airway, especially at the chronic stage, by reducing the production of virulence factors and increasing the capability to form biofilm. Consistent with this notion, $P$. aeruginosa isolates from chronically infected patients exhibited weaker elastase activity than those recovered from colonized CF patients or from pediatric patients without CF [19] and possessed mutations in las $R$ gene [20].

Biofilm formation is a developmental process by which bacteria undergoes significant phenotypic and genetic changes including the acquisition of antibiotic resistance and modulation of growth properties $[21,22,23]$. It is of particular interest that $P$. aeruginosa forms more robust biofilm under anaerobic respiration [17], 
because this demonstrates a resistant mode of bacterial proliferation under a condition that specifically represents the abnormal CF airway. Among many determinants that contribute to biofilm maturation, initial surface attachment $[17,24]$ and secretion of matrix molecules [25] are often considered to be critical. In this study, a unique morphological change that occurs specifically under anaerobic growth and thus influences biofilm formation was observed for the first time in $P$. aeruginosa. Wild type PAOl was highly elongated during anaerobic respiration and an elongationdefective mutant formed very weak biofilm. Cell elongation was attributable to the organism's response to nitric oxide (NO). Ultimately, this observation may form a basis for deciphering the mechanisms by which $P$. aeruginosa modulates its pathogenic properties under anaerobic growth condition.

\section{Materials and Methods}

\section{Bacterial strains and growth conditions}

Wild type $P$. aeruginosa strain PAOl and mucoid strain FRD1 have been previously described [26]. $P$. aeruginosa transposon insertion mutants, $\Delta$ narG, $\Delta$ nir $S, \Delta$ nor $C$ and $\Delta$ anr mutant strains were purchased from a $P$. aeruginosa transposon mutant library (http://www.genome.washington.edu/UWGC/pseudomonas) and sequence verified. L-broth (LB, $10 \mathrm{~g}$ tryptone, $10 \mathrm{~g} \mathrm{NaCl}, 5 \mathrm{~g}$ yeast extract per liter) was used to grow bacteria. Anaerobic bacterial growth was achieved using a GasPak anaerobic system (Becton, Dickinson and Company, Franklin Lakes, NJ) or in a Coy anaerobic chamber (Coylab Inc. Grass Lake, MI). The gas composition inside the anaerobic chamber was a trimix of nitrogen, hydrogen, and carbon dioxide (90, 5, and 5\%, respectively). Dry anaerobic indicator strip (Becton, Dickinson and Company) was used to confirm the generation of anaerobic atmosphere inside the jar. In addition, no detectable growth of $\mathrm{PAO} 1$ in plain $\mathrm{LB}$ was confirmed in each anaerobic experiment. To support anaerobic growth, $\mathrm{KNO}_{3}$ or $\mathrm{NaNO}_{2}$ (Sigma-Aldrich) was added to the medium. When required, $\mathrm{pH}$ of the $\mathrm{LB}$ medium was adjusted to $\mathrm{pH} 7.8$ using $50 \mathrm{mM}$ phosphate.

\section{Scanning Electron Microscope and cell length measurement}

Bacterial cells were visualized by scanning electron microscope (SEM) and confocal microscope. For the sample preparation of SEM, bacterial suspension was fixed with PBS containing $2 \%$ glutaraldehyde and $0.1 \%$ paraformaldehyde for $2 \mathrm{hrs}$ and stained with $1 \% \mathrm{OsO}_{4}$. Samples were then coated with gold by an ion sputter (IB-3 Eiko, Japan) and examined with a scanning electron microscope (FE SEM S-800, Hitachi, Japan) at an acceleration voltage of $20 \mathrm{kV}$. Images were processed with ESCAN 4000 software (Bummi Universe Co., LTD, Seoul, Korea). For the cell length measurement, more than 100 straight-lined cells were randomly chosen in the digitized SEM images and distance between two ends was automatically calculated.

\section{Confocal microscopy}

Differential Interference Contrast (DIC) images were acquired using a confocal laser scanning microscope (FV-1000; Olympus Optical Co. Ltd., Japan) and its operating software, FV10-ASW (ver. 02.01). Prior to the image analysis, aliquots of bacterial cultures were washed with PBS and mounted in wells of 8-well Lab-Tek ${ }^{\mathrm{TM}}$ chambered coverglass (cat. no. 155411, Nalge Nunc International, Rochester, NY). After scanning with $488 \mathrm{~nm}$ laser at a sampling speed of $12.5 \mu$ s/pixel, a $640 \times 640$ pixel, 12-bit image $(57.51 \mu \mathrm{m} \times$ $57.51 \mu \mathrm{m}$ ) was acquired. UPLSAPO 100XO (Olympus) objective lens was used for the bacterial cell image analysis. Images were saved as a TIF file with embedded $5 \mu \mathrm{m}$ scale bar.

For the membrane visualization, $\mathrm{PAO} 1$ grown in $\mathrm{LB}$ plus $0.4 \%$ $\mathrm{NO}_{3}{ }^{-}$to the early stationary phase under aerobic or anaerobic condition was washed with PBS and the cells were resuspended in $200 \mu \mathrm{l}$ of PBS containing $10 \mu \mathrm{M}$ of the lipophilic membrane dye TMA-DPH (Invitrogen Corp. Carlsbad, CA). Again, 8-well Lab$\mathrm{Tek}^{\mathrm{TM}}$ chambered coverglass (cat. no. 155411, Nalge Nunc International) was used to mount samples on the objective lens. Image acquisition was conducted as described for the DIC image analysis except that samples were scanned at $405 \mathrm{~nm}$ and emissions were collected at $461 \mathrm{~nm}$.

For the nucleoid staining, Syto 9 green fluorescent dye (Invitrogen Corp. Carlsbad, CA) was used at $10 \mu \mathrm{M}$ final concentration. To capture the green fluorescence, samples were scanned at $488 \mathrm{~nm}$ and emission was detected through a $520 \mathrm{~nm}$ band filter. The DIC and green fluorescence images were collected simultaneously.

\section{Counting the cluster formation in the planktonic culture of $P$. aeruginosa strains}

To count the number of clusters, $20 \mu \mathrm{l}$ of each bacterial culture was pipetted onto the slide glass. A $22 \times 40 \mathrm{~mm}$ coverslip (Paul Marienfeld GmbH \& Co. KG, Lauda-Koenigshofen, Germany) was then placed over the rectangular area of the slide glass. Nikon SE optical microscope (Nikon Vision Co., Ltd) was used to view and count the number of clusters in the sample. Cluster counting was performed while the objective lens was manually moved from the top left to the bottom right region of the coverslip. Aggregates that consist of more than 10 cells were considered as clusters.

\section{Biofilm assays}

The ability of $P$. aeruginosa to develop biofilm was assessed with a modified microtiter plate assay as described previously [24]. Briefly, $P$. aeruginosa aerobic preculture grown in LB was inoculated (1:100 dilution) into the anaerobic culture media (i.e. LB containing $\mathrm{NO}_{3}{ }^{-}$or $\mathrm{NO}_{2}{ }^{-}$) in 24-well or 96-well plates and incubated anaerobically for $18 \mathrm{hrs}$ at $37^{\circ} \mathrm{C}$ without agitation. Biofilm formed by $P$. aeruginosa strains was stained with $0.1 \%$ crystal violet $(\mathrm{CV})$ and the stained $\mathrm{CV}$ was dissolved in $95 \%$ ethanol for measurement of the absorbance at $540 \mathrm{~nm}$. Because the capacity to form biofilm is proportional to the bacterial cell growth, $\mathrm{OD}_{540 \mathrm{~nm}}$ was normalized with cell mass determined by measuring $\mathrm{OD}_{600 \mathrm{~nm}}$. To test the effect of antibiotic treatment on the biofilm formation, sub-MIC concentrations of carbenicillin, tobramycin or ciprofloxacin were added to the aerobic PAOl culture in 96-well plates. The minimal inhibitory concentration (MIC) of selected antibiotics was determined as described previously [27].

\section{Quantitative real time-PCR (qRT-PCR) analysis}

Aliquots $(1.5 \mathrm{ml})$ of bacterial cell cultures were harvested by spinning down at $14,000 \mathrm{rpm}$ for $5 \mathrm{~min}$. Pelleted cells were resuspended with $1 \mathrm{ml}$ of Trizol (Invitrigen) and then $0.2 \mathrm{ml}$ of chloroform was added. After incubating $5 \mathrm{~min}$ at room temperature, Trizol-chloroform mixture was centrifuged for $10 \mathrm{~min}$ at $4^{\circ} \mathrm{C}$ to separate the aqueous phase containing RNA. The rest of RNA purification steps were carried out using RNeasy kit (Qiagen) following the manufacturer's instruction. The extracted RNA samples were subjected to PGR to verify the absence of contaminating DNA. The resulting RNA samples were quantified using a Nanodrop spectrophotometer (model no. ASP2680, CellTAGen Inc., Seoul Korea). For cDNA synthesis, $2 \mu \mathrm{g}$ RNA template was mixed with $1 \mu \mathrm{l}$ of 100 pmoles/ $\mu \mathrm{l}$ random primer 
(5'-NSNSNSNSNS-3', where $\mathrm{N}=\mathrm{A}, \mathrm{T}, \mathrm{C}$, or $\mathrm{G}$ and $\mathrm{S}=\mathrm{C}$ or $\mathrm{G}$ ) and dNTP mix in $15 \mu$ total volume. The mixture was then treated at $65^{\circ} \mathrm{C}$ for $5 \mathrm{~min}$, followed by $5 \mathrm{~min}$ incubation on ice. Next, one unit of Primescript reverse transcriptase (Takara Bio Inc., Shiga, Japan) was added with $1 \mu$ of $5 x$ primescript reaction buffer and $13 \mu$ DEPG-treated water. The mixture was then incubated at $42^{\circ} \mathrm{C}$ for $1 \mathrm{hr}$ and at $70^{\circ} \mathrm{C}$ for $15 \mathrm{~min}$. Real time PCR reaction was monitored using StepOne Real-time PGR system (Applied Biosystems, Carlsbad, CA). For the reaction, SYBR premix Ex Taq (Takara) was used following the manufacturer's instructions. Primer sets used to amplify cDNA are listed in Table S1. The PCR cycle was $95^{\circ} \mathrm{C}$ for $10 \mathrm{~min}$ and 40 cycles of $95^{\circ} \mathrm{C}$ for $20 \mathrm{~s}$ and $60^{\circ} \mathrm{C}$ for $20 \mathrm{~s}$, followed by $95^{\circ} \mathrm{C}$ for $15 \mathrm{~s}$ and $60^{\circ} \mathrm{C}$ for $1 \mathrm{~min}$. Transcript levels of $r p_{0} D$ gene were similar in cells grown by either aerobic or anaerobic respiration and thus, used for the normalization.

Statistical analysis. Data are expressed as mean \pm SEM (standard error of mean). An unpaired Student's $t$-test was used to analyze the data. A $p$-value of $<0.05$ was considered statistically significant. All the experiments were repeated for reproducibility.

\section{Results}

Cell elongation occurs in PAO1 grown by anaerobic respiration using $\mathrm{NO}_{3}$ as an alternative electron acceptor

Understanding cell biological features of $P$. aeruginosa that occur specifically upon anaerobic respiration would provide a better insight into the bacterial pathogenic mechanisms under such condition. To address this important question, we first investigated cellular morphology of PAO1 grown aerobically or anaerobically by scanning electron microscope. When grown in LB with aeration, PAOl exhibited normal rod shape morphology with a cell length of $\sim 1.2 \mu \mathrm{m}$ (Fig. 1A). The addition of $0.4 \% \mathrm{NO}_{3}{ }^{-}$to the culture medium did not cause any detectable change in cell shape (Fig. 1B). In contrast, $\mathrm{PAOl}$ grown by $\mathrm{NO}_{3}{ }^{-}$respiration under anaerobic condition was highly elongated (Fig. 1D) compared to aerobically grown cells. Software-aided cell length measurement clearly demonstrated that cells are highly elongated upon anaerobic $\mathrm{NO}_{3}{ }^{-}$respiration $(\sim 5.2 \mu \mathrm{m}$ vs. $\sim 1.2 \mu \mathrm{m}$, Fig. 1E). Cell elongation did not occur in PAOl incubated anaerobically for the same period of time in growth medium that lacked $\mathrm{NO}_{3}{ }^{-}$(Fig. 1C). No discernable growth was observed in this particular culture further proving that the presence of alternative electron acceptor is crucial for anaerobic growth in $P$. aeruginosa (Fig. S1, hatched bar). In addition, no similar elongation was observed in anaerobic cultures of mutant bacteria disrupted in nitric oxide (NO) reductase $(\triangle$ nor $C B$, Fig. 1G) or ANR, one of the master anaerobic transcriptional regulators $(\Delta a n r$, Fig. $1 \mathrm{H})$. These two mutant strains were defective in anaerobic respiration and thus no anaerobic growth was detected in previous works $[6,28]$. It was also reported that $P$. aeruginosa can support, to a lesser extent, anaerobic growth by arginine fermentation [29]. As shown in Fig. 1I, no elongation was observed in cells grown by arginine fermentation. Together, these results suggest that cell elongation is caused by an active bacterial response to anaerobic
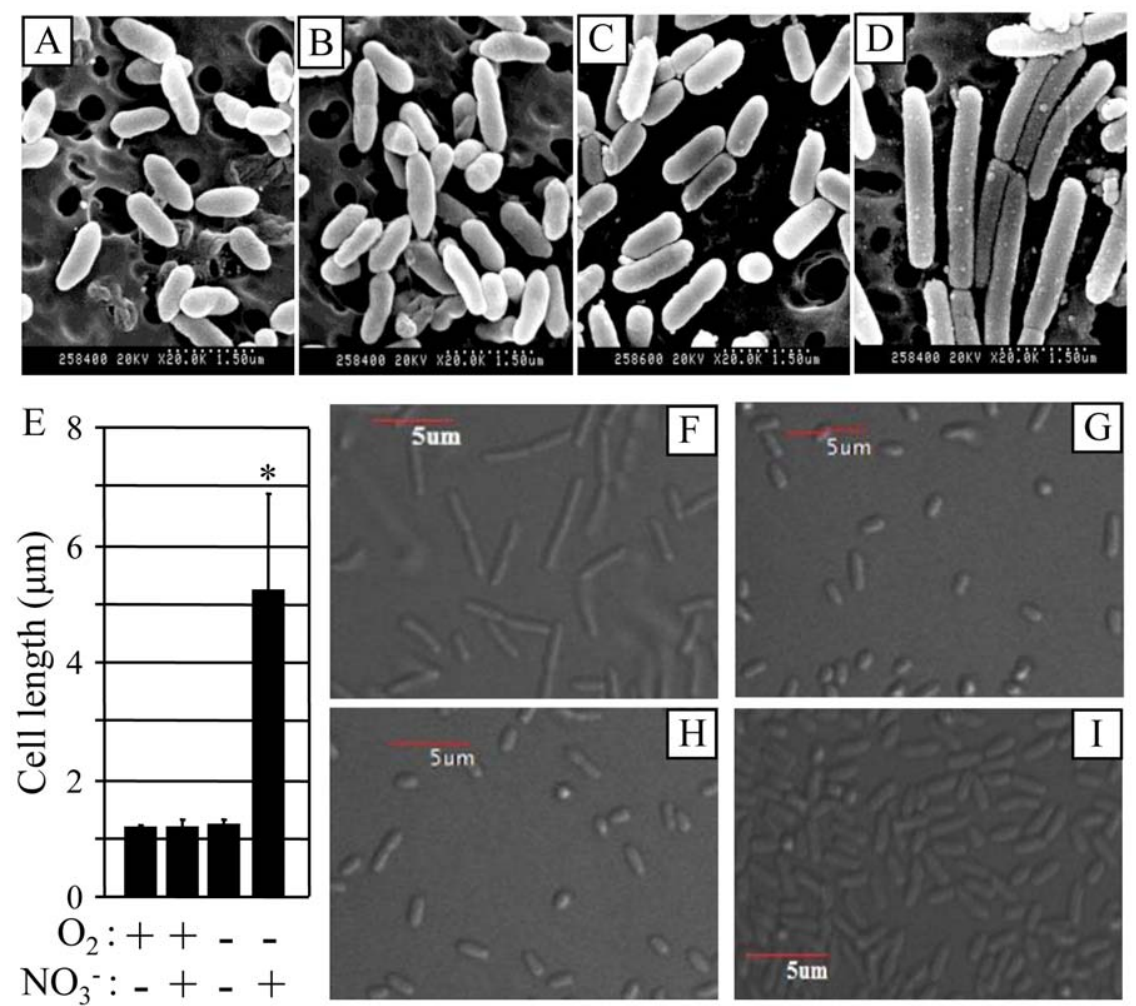

Figure 1. $\mathrm{NO}_{3}{ }^{-}$respiration-induced cell elongation of PAO1. (A-D) Scanning electron microscope (SEM) images of PAO1 grown in LB (A and C) or LB containing $0.4 \% \mathrm{NO}_{3}{ }^{-}$(B and $\mathbf{D}$ ) either aerobically (A and $\mathbf{B}$ ) or anaerobically (C and $\left.\mathbf{D}\right)$. Cells were grown for 15 hours prior to processing for SEM. The images were acquired at a magnification of 20,000 and scale bar of $1.5 \mu \mathrm{m}$ is indicated at the bottom right. (E) Cell length was determined with software-aided distance measurement as described in experimental procedures. For statistical significance, more than 100 cells were selected for measurement in each image and mean \pm SEM (standard error of mean) was presented. ${ }^{*} p<0.001$ vs. cells shown in the other three images. $(\mathbf{F}-\mathbf{H})$ DIC images of PAO1 $(\mathbf{F}), \Delta$ norC $(\mathbf{G})$ and $\triangle a n r(\mathbf{H})$ grown in $\mathrm{LB}+0.4 \% \mathrm{NO}_{3}{ }^{-}$under anaerobic environment. (I) DIC image of PAO1 grown in $\mathrm{LB}+30 \mathrm{mM}$ arginine under anaerobic environment. Acquisition of DIC images was conducted as described in materials and methods. doi:10.1371/journal.pone.0016105.g001 
A

$+\mathrm{O}_{2}$

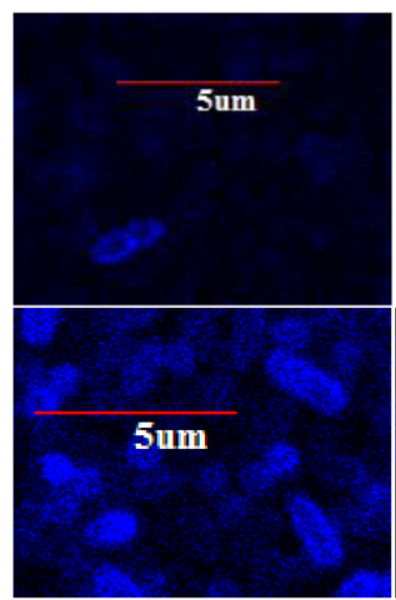

$\mathrm{B} \quad-\mathrm{O}_{2}$
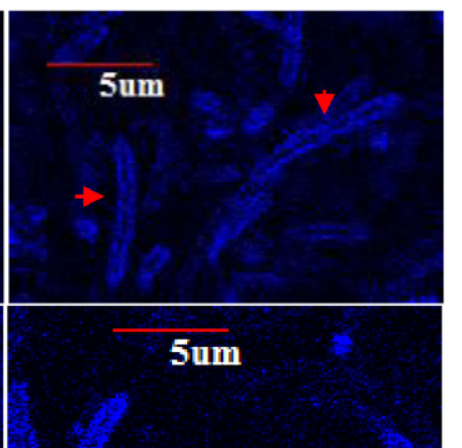

5um
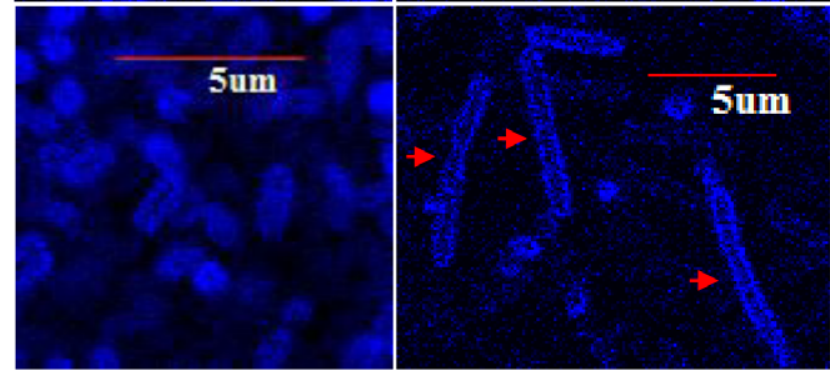

Figure 2. Confocal microscopic image analysis of cell membrane of elongated $P$. aeruginosa. PAO1 grown in $\mathrm{LB}+0.4 \% \mathrm{NO}_{3}$ either aerobically (A) or anaerobically (B) was stained with $10 \mu \mathrm{M}$ TMADPH for the visualization of cell membrane. Three different images per sample are displayed. $5 \mu \mathrm{m}$ scale bars were incorporated to clearly compare the cell length between two cultures. Red arrows indicate highly elongated cells. Image analysis was performed as described in materials and methods.

doi:10.1371/journal.pone.0016105.g002

respiration and not a consequence of bacterial exposure to anaerobic environments and arginine fermentation.

\section{Cell elongation is likely caused by defective cell division}

Fig. 1D revealed that most of elongated cells are free of invaginated cell wall pattern, which may indicate that the formation of septal peptidoglycan [30] is suppressed in PAOl grown by anaerobic respiration. To gain a better idea of the membrane structure of elongated cells, we visualized bacterial cells stained with TMA-DPH, a lipophilic dye that specifically binds to cell membrane and thus outlines the cell periphery [31]. As shown in Fig. 2B, PAOl grown by anaerobic respiration was highly elongated compared with that grown by aerobic respiration (Fig. 2A) further validating the results described in Fig. 1. It is of interest that continuous staining throughout the entire cell envelope was observed in elongated bacteria as indicated with red arrows (Fig. 2B). Moreover, no clear pattern of cleavage furrow formation was detected in the same cell images. This result strongly suggests that normal cellular machinery for the cell division is affected in these anaerobically grown bacteria.

It was reported that inhibition of chromosomal DNA replication by UV irradiation caused a cell elongation phenotype in E. coli [32]. Therefore, we sought to examine whether or not the replication of chromosomal DNA occurred normally in such elongated cells. To address this issue, we stained the cells with syto
9, a cell-permeant green fluorescence dye that specifically stains nucleic acid. In aerobically grown and thus rod-shaped cells, fluorescent signal was detected in the entire area of cell further suggesting that bacterial genome is not limited within a membrane-enclosed suborganelle (Fig. 3A, $\mathrm{O}_{2}$ ). Interestingly, multiple segregating nucleoids were observed in most of elongated cells (Fig. 3B, $-\mathrm{O}_{2}$ ). When we compared identical fields of images acquired by DIC or syto 9 staining side by side, distinctly segregated nucleoids were detected in elongated cells (red arrows in Fig. 3B). Together, these image analyses strongly suggest that cell elongation is due not to defects in DNA replication or chromosome segregation, but to the incomplete septum formation.

Next, we compared the transcript levels of representative genes involved in cell division and cell wall synthesis by quantitative real time PCR (qRT-PCR). We first analyzed zipA (PA1528), fts Z (PA4407) and ftsA (PA4408), because formation of Z-ring, which requires the cooperative assembly of FtsZ, FtsA and ZipA at the mid-cell region is essential for the initiation of cell division process [33]. Transcript level of $r p o D$ gene, which exhibited almost identical level of expression under aerobic or anaerobic growth, was used as a normalization control. As shown in Fig. 4, expression of zipA gene was $\sim 3$-fold lower in PAOl grown by anaerobic respiration than in aerobically grown PAOl. A more than 10-fold decrease was observed in transcript levels of both fts $Z$ and fts $A$ during anaerobic vs. aerobic respiration. We then examined transcript levels of murD (PA4414) and murF (PA4416) genes encoding UDP-N-acetylmuramoylalanine-D-glutamate ligase and UDP-N-acetylmuramoylalanyl-D-glutamyl-2,6-diaminopimelate-D-alanyl-D-alanyl ligase, two important enzymes involved in peptidoglycan synthesis. Likewise, transcript levels of these two genes in PAOl grown by anaerobic respiration were only $\sim 13 \%$ of those achieved in cells grown by aerobic respiration. This result suggests that expression of genes involved in Z-ring formation and peptidoglycan synthesis, two critical steps for the optimal cell division, is significantly reduced during the anaerobic growth in $P$. aeruginosa.

\section{Functional nitrite reductase (NIR) is required for anaerobiosis-triggered cell elongation}

Anaerobic respiration in $P$. aeruginosa involves a sequential reduction of nitrate $\left(\mathrm{NO}_{3}{ }^{-}\right)$or nitrite $\left(\mathrm{NO}_{2}{ }^{-}\right)$to $\mathrm{N}_{2}$ [6]. Higher cell yield was obtained in PAOl growth using $\mathrm{NO}_{3}{ }^{-}$as an electron acceptor than $\mathrm{NO}_{2}{ }^{-}$-supported anaerobic growth (Fig. $\mathrm{S} 1$ ), suggesting that $\mathrm{NO}_{3}{ }^{-}$reduction is the major step that is coupled to ATP synthesis in wild type $P$. aeruginosa. Since cell elongation only occurred in anaerobically respiring $P$. aeruginosa, the anaerobic respiration pathway was further dissected to uncover the crucial step that is responsible for cell elongation. To address this issue, cell elongation phenotypes of $\Delta n a r G$ and $\Delta n i r S$ mutant, which became defective in NAR or NIR, respectively, were tested (Fig. 5A). Consistent with findings described in Fig. 1, wild type strain PAOl and two mutant strains grown by aerobic respiration maintained their regular rod-shape morphology even in the presence of $15 \mathrm{mM} \mathrm{NO}_{3}{ }^{-}$(Fig. 5B, $\mathrm{E}$ and $\mathrm{H}$ ). PAOl anaerobically grown on $\mathrm{NO}_{3}{ }^{-}$(Fig. 5C) or $\mathrm{NO}_{2}{ }^{-}$(Fig. 5D) was invariably elongated compared to its aerobically grown counterpart (Fig. 5B). This suggests that anaerobic growth supported by either electron acceptor can trigger cell elongation in $P$. aeruginosa. To minimize the growth-inhibitory effect of $\mathrm{NO}_{2}{ }^{-}$on bacterial growth [26], the $\mathrm{pH}$ of the culture medium was adjusted to 7.8, when $\mathrm{NO}_{2}{ }^{-}$is used as an electron acceptor. It was important to note that the $\Delta$ nar $G$ and $\Delta$ nir $S$ mutants did not grow on $\mathrm{NO}_{3}{ }^{-}$or $\mathrm{NO}_{2}{ }^{-}$, respectively, due to the lack of the enzyme that can reduce the corresponding electron acceptor (Fig. S1) and thus, no cell 


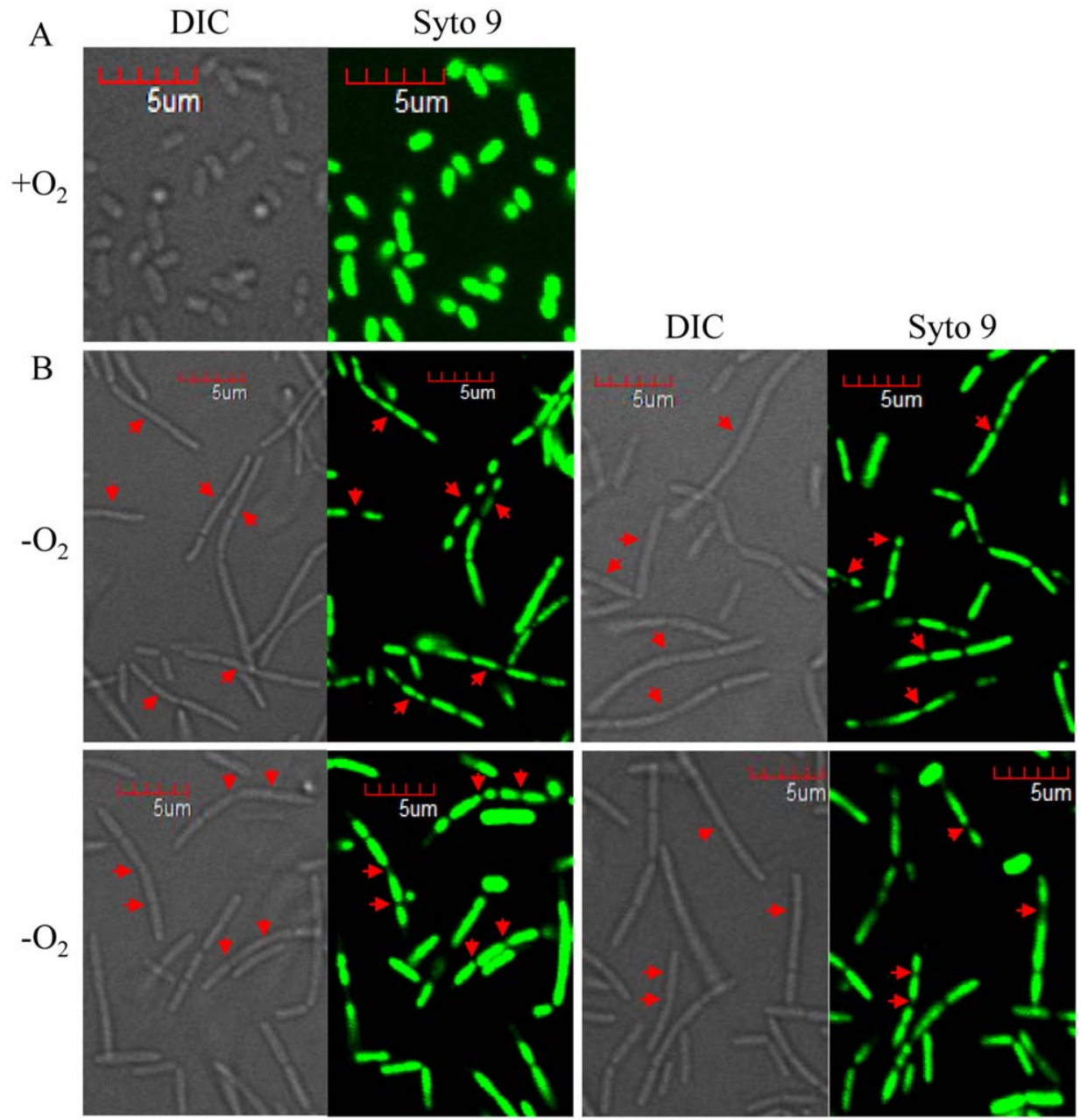

Figure 3. Elongated cells contain multiple nucleoids. $\mathrm{PAO} 1$ grown in $\mathrm{LB}+0.4 \% \mathrm{NO}_{3}{ }^{-}$either aerobically (A) or anaerobically (B) was stained with $10 \mu \mathrm{M}$ Syto9, a green fluorescent dye that specifically binds to nucleic acid. Stained cells were analyzed by confocal microscopy as described in materials and methods. Simultaneously collected DIC images were shown together side by side to display the identical field of cells. Red arrows indicate the same location in a pair of cells in DIC and Syto 9 green fluorescent images.

doi:10.1371/journal.pone.0016105.g003

elongation was observed in each of these two anaerobic cultures (Fig. 5F and $\mathrm{J}, *$ denotes no growth). This result further validates that active respiratory growth is the prerequisite for the cell elongation during anaerobic growth. Importantly, $\Delta$ nar $G$ mutant bacteria grown by $\mathrm{NO}_{2}{ }^{-}$respiration were as elongated as its parental strain, PAOl (Fig. 5G), whereas $\Delta$ nirS mutant cells were not elongated upon anaerobic growth on $\mathrm{NO}_{3}{ }^{-}$(Fig. 5I). Final cell density in these two cultures was comparable to each other (Fig. $\mathrm{S} 1$ ), suggesting that the formation of these two contrasting cell shapes (Fig. 5G vs. 3I) was not caused by the differential bacterial cell growth.

Moreover, mucoid $P$. aeruginosa, FRD1, determined to possess undetectable NIR activity [26], was not elongated under the same $\mathrm{NO}_{3}{ }^{-}$respiring condition (Fig. S2). Together, these results suggest that NIR-mediated reduction of $\mathrm{NO}_{2}{ }^{-}$to $\mathrm{NO}$ is the critical step that triggers anaerobiosis-induced cell elongation in $P$. aeruginosa.

\section{Biofilm formation of the non-elongated $\Delta$ nirS mutant was significantly reduced under the $\mathrm{NO}_{3}{ }^{-}$respiring condition}

It has been previously shown that during anaerobic respiration, $P$. aeruginosa formed significantly more robust biofilm compared to when bacteria grow aerobically $[17,18]$. This finding was successfully reproduced in our crystal violet biofilm staining assay as shown in Fig. 6A. Since elongated cell morphology was only observed under anaerobic respiration condition, we sought to examine if this enhanced biofilm formation is caused by a modified cell biological feature associated with cell elongation. To address this question, the biofilm formation of $\Delta$ nar $G$ and $\Delta$ nir $S$ mutants that showed distinct cell elongation phenotypes were compared (Fig. 5G and I). pH-buffered L-Broth media was used to maximize bacterial growth by $\mathrm{NO}_{2}{ }^{-}$respiration. Wild type PAOl formed very robust biofilm in both $\mathrm{NO}_{3}{ }^{-}$and $\mathrm{NO}_{2}{ }^{-}$-stimulated anaerobic growth (Fig. 6B). Quantification analysis of biofilm formation by measuring $\mathrm{OD}_{540 \mathrm{~nm}} / \mathrm{OD}_{600 \mathrm{~nm}}$, however, indicated that denser biofilm was formed under the condition of $\mathrm{NO}_{3}{ }^{-}$ respiration than $\mathrm{NO}_{2}{ }^{-}$respiration (Fig. 6C). This was likely due to greater bacterial growth by $\mathrm{NO}_{3}{ }^{-}$respiration (Fig. S1). It is important to note that the $\Delta$ nar $G$ mutant, which was elongated during anaerobic growth using $\mathrm{NO}_{2}{ }^{-}$as an electron acceptor (Fig. 5G), formed biofilm that was almost as robust as the PAOl biofilm under the same growth conditions (Fig. 6B). In contrast, biofilm formation was completely abrogated in the non-elongated $\Delta$ nirS mutant upon $\mathrm{NO}_{3}{ }^{-}$respiration (Fig. 6B). Again, this distinct 

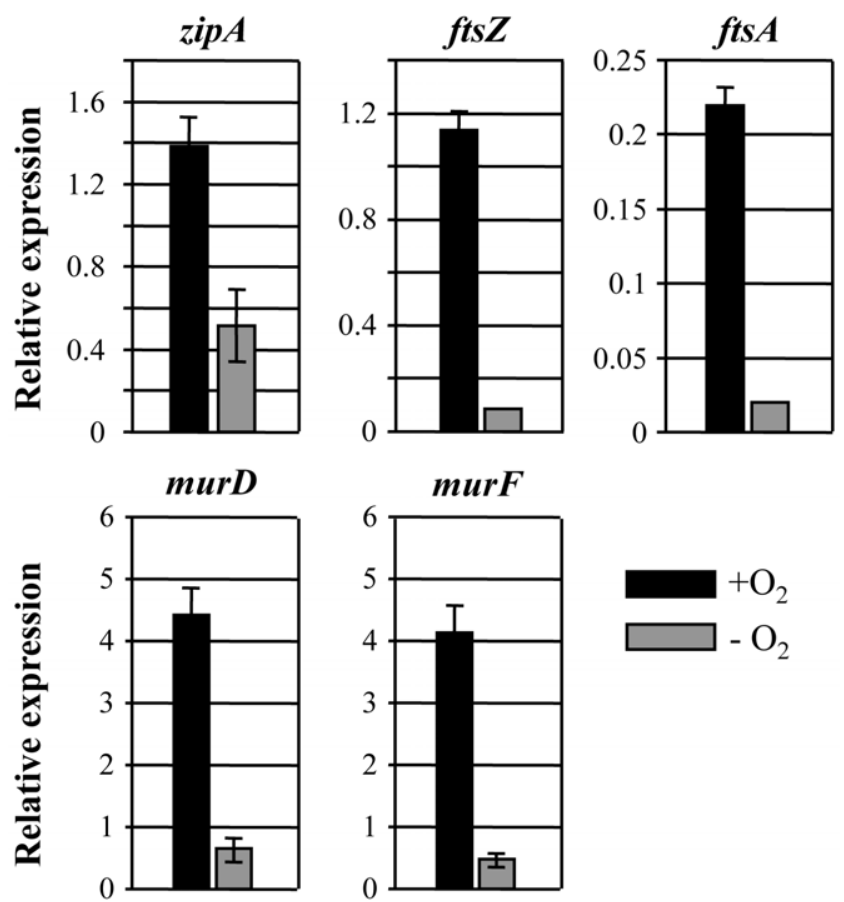

Figure 4. Quantitative RT-PCR analysis of genes involved in cell division and peptidoglycan synthesis. QRT-PCR was conducted on cDNA synthesized from $2 \mu \mathrm{g}$ total RNA extracted from PAO1 grown either aerobically (black bars) or anaerobically (gray bars). Transcript levels of 5 genes indicated on top of each graph were normalized with levels of the $r p o D$ transcript. Three independent experiments were performed and values of mean \pm SEM are displayed in each bar. doi:10.1371/journal.pone.0016105.g004

biofilm formation was not due to the differential growth of these two anaerobic cultures, because cell growth of the $\Delta$ nirS mutant on $\mathrm{NO}_{3}{ }^{-}$was slightly greater than the $\Delta$ nar $G$ mutant in $\mathrm{NO}_{2}{ }^{-}$(Fig. $\mathrm{S} 1)$. As expected, anaerobic cell growth of $\Delta \operatorname{nar} G$ on $\mathrm{NO}_{3}{ }^{-}$or $\Delta$ nir $S$ on $\mathrm{NO}_{2}{ }^{-}$was minimal and thus, no biofilm was formed in each of these two cultures. These results suggest that anaerobiosisinduced cell elongation, which is dependent on the presence of NIR activity, plays a critical role in robust biofilm formation under these conditions.

\section{Cell elongation and biofilm formation were both suppressed in the presence of Carboxy-PTIO, a stoichiometric scavenger in PAO1}

Although nitric oxide (NO), the product of NIR, is further reduced to $\mathrm{N}_{2} \mathrm{O}$, steady-state level of nitric oxide $(\mathrm{NO})$ is maintained during anaerobiosis [16,34]. Since (i) NIR activity, which generates $\mathrm{NO}$ as its product, is required for cell elongation as shown in Fig. 5, and (ii) the enzymatic action of NIR is the only source of NO production under anaerobic growth conditions [6], it was postulated that production of intracellular NO may account for the anaerobiosis-induced cell elongation. To address this notion, the cell elongation phenotype of PAO1 grown in the presence of $2 \mathrm{mM}$ carboxy-PTIO, a stoichiometric NO scavenger was tested. In our previous work, carboxy-PTIO, which penetrates the periplasm and scavenges $\mathrm{NO}$ before it escapes to the cytoplasm or is reduced by NOR, successfully protected $P$. aeruginosa strains from NO-mediated intoxication [17]. As shown in Fig. 7A and B, cell elongation was suppressed in the presence of carboxy-PTIO $(4.87 \pm 1.89 \mu \mathrm{m}$ vs. $2.35 \pm 0.54 \mu \mathrm{m})$.
Results described in Fig. 6 indicate that cell elongation is an important cellular event that contributes to the biofilm formation under the condition of anaerobic respiration. To further prove the effect of cell elongation on biofilm formation, biofilm formation in a condition where cell elongation was hindered by the addition of carboxy-PTIO was examined. As shown in Fig. 7C, a dosedependent decrease in biofilm formation was detected in the presence of increasing amount of carboxy-PTIO. Upon growth with $2 \mathrm{mM}$ carboxy-PTIO, biofilm robustness was $\sim 47 \%$ of that of the control anaerobic biofilm suggesting that the perturbation of cell elongation exerted an adverse effect on biofilm formation. No adverse effect of added carboxy-PTIO on cell viability was observed up to $2 \mathrm{mM}$ concentration (data not shown).

Clump formation was induced during anaerobic growth

Importantly, we often observed highly cohesive cell clusters in the elongated $P$. aeruginosa. Fig. 8A shows a representative image of clusters formed by PAOl during an anaerobic planktonic culture. When we attempted to quantify the cluster formation in anaerobic vs. aerobic cultures of PAO1, $\sim 30( \pm 14)$ clusters per $20 \mu \mathrm{l}$ of overnight culture that was mounted on the slide glass were identified in our microscopic analysis. Similar clusters were detected neither in the aerobic $P$. aeruginos a cultures nor anaerobic $\Delta$ nirS mutant culture (data not shown). This data strongly suggest that cell elongation that specifically occurs during anaerobic respiration is involved in the cohesive clump formation that eventually leads to the robust biofilm formation.

Two distinct genetic loci, pel and psl produce carbohydrate-rich biofilm matrix that can hold bacterial cells together [35,36,37]. Therefore, it is of interest to examine whether Pel and/or Psl polysaccharide matrix could contribute to the anaerobiosisinduced clump formation. As a way to address this issue, we performed qRT-PCR on pelE and $p s l B$, genes representing each of these two clusters. Shown in Fig. $8 \mathrm{~B}$ is the transcriptional modulation of these two genes under aerobic vs. anaerobic growth conditions. Transcription of pelE gene was not changed upon anaerobic growth, while the transcript level of $p s l B$ gene was decreased to $\sim 20 \%$ of what was observed in cells grown aerobically. This result suggested that levels of Pel and/or Psl polysaccharides produced during anaerobic respiration would not be higher than those produced during aerobic growth and thus, anaerobiosis-induced enhancement of clump formation is not likely to be associated with altered production of extracellular polysaccharides.

\section{Biofilm formation was promoted in the presence of carbenicillin that induced cell filamentation}

Our results suggest that robust anaerobic biofilm formation is likely mediated by modified cellular features associated with anaerobiosis-specific cell elongation in $P$. aeruginosa. To provide further evidence that supports the correlation between cell elongation and biofilm formation in $P$. aeruginosa, we tested if biofilm formation can also be promoted by other stimulus that causes cell elongation. Because cell elongation occurs upon treatment with carbenicillin in $P$. aeruginosa $[38,39,40]$, we compared biofilm formation of PAOl treated with carbenicillin versus ciprofloxacin and tobramycin. As shown in Fig. 9, biofilm formation of PAOl was significantly increased in the presence of sublethal doses of carbenicillin. In our microscopic analysis, a high degree of cell filamentation was also observed confirming results from aforementioned referenced studies (data not shown). It is of note that PAOl was highly resistant to carbenicillin and MIC was determined to be $750 \mu \mathrm{g} / \mathrm{ml}$, a value consistent with previous findings $[40,41]$. In contrast, only a mild increase in biofilm 
A

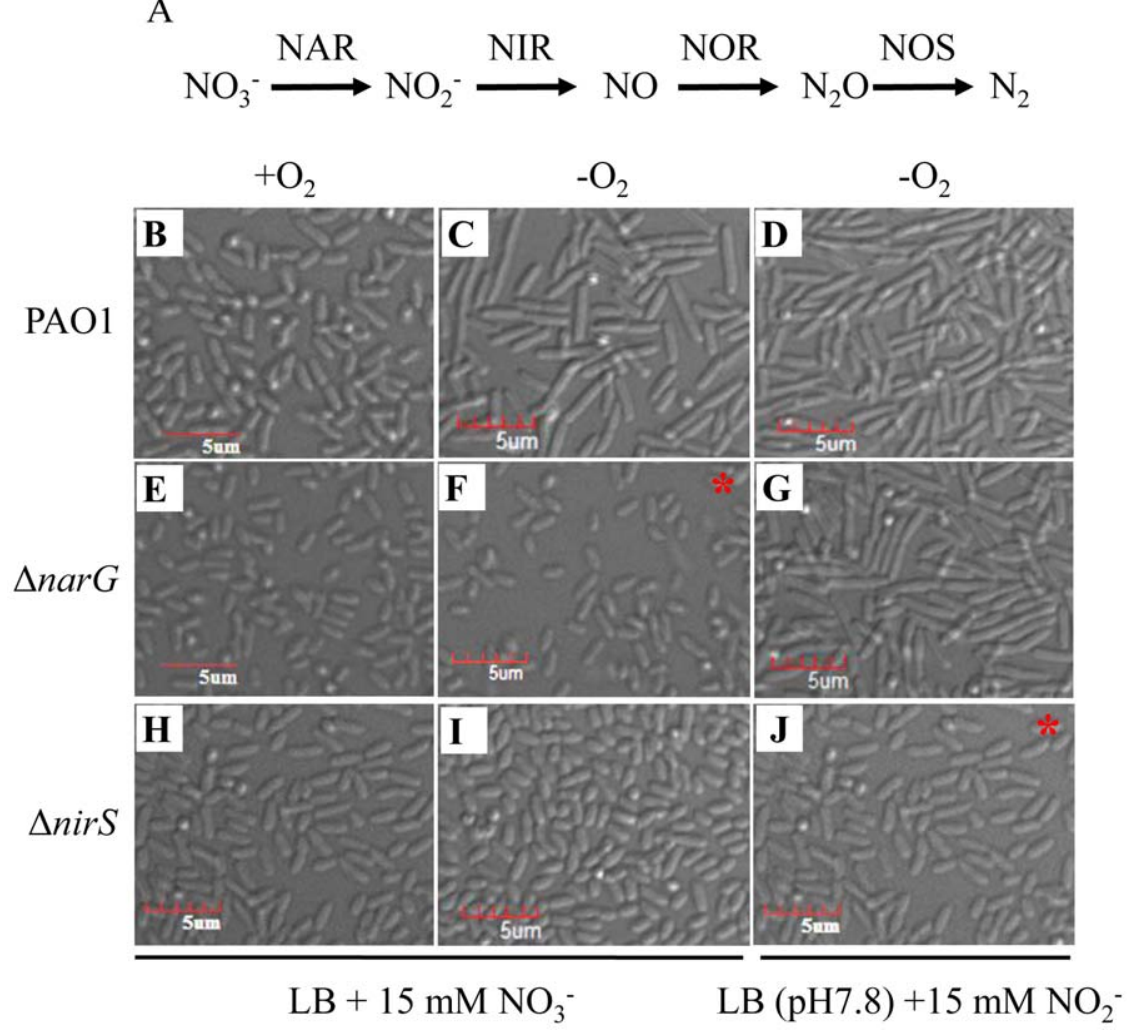

Figure 5. Cell elongation phenotypes of $P$. aeruginosa mutant strains under aerobic and anaerobic growth conditions. (A) Anaerobic respiratory (denitrification) pathway. Enzymes involved in each reduction step are termed nitrate reductase (NAR), nitrite reductase (NIR), nitric oxide

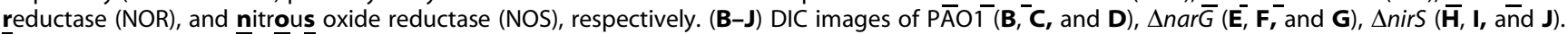
Bacterial strains were grown for 18 hours in $\mathrm{LB}+15 \mathrm{mM} \mathrm{NO}_{3}{ }^{-}$aerobically $(\mathbf{B}, \mathbf{E}$, and $\mathbf{H})$, anaerobically $(\mathbf{C}, \mathbf{F}$, and $\mathbf{I})$, and anaerobically in $\mathrm{LB}(\mathrm{pH} 7.8)$ $+15 \mathrm{mM} \mathrm{NO}_{2}{ }^{-}$(D, G, and $\left.\mathbf{J}\right)$. A scale bar of $5 \mu \mathrm{m}$ is indicated in the bottom left of each panel. * No discernible growth was observed in these two cultures and thus, cells were concentrated for image acquisition.

doi:10.1371/journal.pone.0016105.g005

formation was observed in PAOl treated with tobramycin or ciprofloxacin (Fig. 9). No cell shape change was observed in aerobic growth with each of these two antibiotics (data not shown). This result demonstrated that treatment with an antibiotic that specifically induced cell elongation also promoted biofilm formation further suggesting the positive influence of cell elongation on biofilm formation in $P$. aeruginosa.

\section{Discussion}

Biofilm is a microbial community grown as an aggregate or on a surface with distinct architecture [23]. Biofilm research using $P$. aeruginosa as a model organism has been performed using in vitro biofilm grown under aerobic respiration. Although the presence of local regions with reduced oxygen potential has been proposed to exist inside bacterial biofilm [42,43], previous works showed that anaerobically growing $P$. aeruginosa formed significantly robust biofilm compared with bacteria growing by aerobic respiration $[17,18]$. This observation is of clinical importance because the airway of chronic CF patients was suggested to be anaerobic due to the accumulation of abnormally thickened and viscous mucus on top of the airway epithelium [8]. In addition, anaerobically growing $P$. aeruginosa exhibited higher resistance to a range of currently used antibiotics than their aerobically grown counterparts [11], further suggesting that $P$. aeruginosa proliferates inside the patient airway by employing two different modes of antibioticresistant growth, i.e. biofilm and anaerobiosis.
The molecular mechanisms behind the enhanced biofilm formation under anaerobic growth conditions are not clearly defined. Here, a unique morphological feature of $P$. aeruginosa grown by anaerobic respiration was identified for the first time and its effect on biofilm formation was investigated. Our results revealed that anaerobic growth of $P$. aeruginosa is concurrently accompanied by abnormally altered cell division. PAO1 grown during anaerobic respiration was $\sim 5$-fold more elongated than aerobically grown cells by a mechanism associated with defective cell division. In $P$. aeruginosa, cell elongation was reported to be caused by nutrient deprivation [44]. It was postulated that bacteria elongate to increase their nutrient uptake as a part of their adaptation process for starvation. However, it seems unlikely that anaerobiosis-induced cell elongation occurred for a similar reason since (i) the cells were grown in rich media (i.e. L-Broth) and (ii) the density at which the culture was harvested for the microscopic image was as low as $\mathrm{OD}_{600}$ of $\sim 0.5$. In addition, $\mathrm{NO}_{3}{ }^{-}$-supported anaerobic growth is considerably luxuriant and thus the final density of an anaerobic culture of wild type PAOl supplemented with $100 \mathrm{mM} \mathrm{NO}_{3}{ }^{-}$was almost comparable with that of aerobic culture (data not shown).

Cell elongation (or filamentation) was also reported to take place under nonpermissive conditions, such as high growth temperature [45], the treatment with certain antibiotics [46] and the UV irradiation [32]. But, bacterial growth under these highly stressful conditions was completely ceased and furthermore, the level of cell elongation appeared to be significantly greater than what was 
A

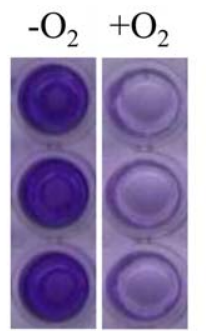

$\mathrm{B}$

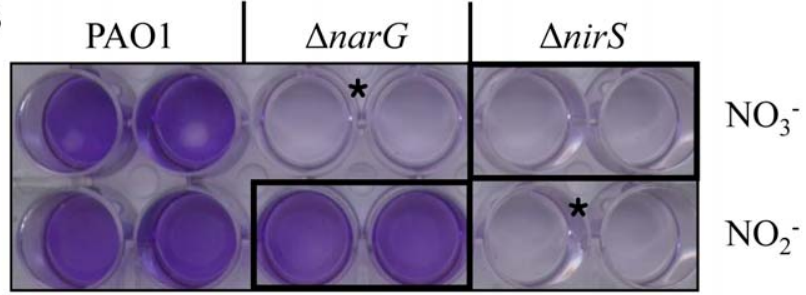

$\mathrm{C}$

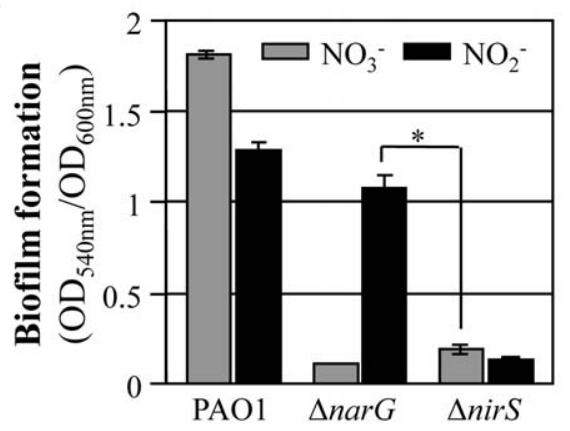

Figure 6. Biofilm formation of the $\Delta$ narG and $\Delta$ nirS mutants during anaerobic respiration using $\mathrm{NO}_{3}{ }^{-}$or $\mathrm{NO}_{2}{ }^{-}$as electron acceptors. (A) Crystal violet (CV) staining of biofilms formed by PAO1 under aerobic and anaerobic respiration conditions. (B) CV staining of biofilms formed by P. aeruginosa strains, PAO1, $\mathrm{narG}$, and $\Delta$ nirS. Strains were grown for 18 hours prior to staining in $\mathrm{pH}$-adjusted LB media containing either $15 \mathrm{mM}$ $\mathrm{NO}_{3}{ }^{-}$(top row) or $\mathrm{NO}_{2}^{-}$(bottom row). CV staining was performed as described in materials and methods. *No discernible growth was observed in these two cultures. (C) Quantification of the $\mathrm{CV}$ staining. $\mathrm{OD}_{540 \mathrm{~nm}}$ values were normalized with cell mass measured by $\mathrm{OD}_{600 \mathrm{~nm}} \cdot{ }^{*} \mathrm{p}<0.001 \mathrm{vs}$. biofilms formed by the $\Delta$ nirS mutant.

doi:10.1371/journal.pone.0016105.g006

observed in the present study. This suggests that although $P$. aeruginosa favors the utilization of oxygen to generate energy and can grow faster aerobically, cells are not placed under any stress condition in the absence of oxygen and thus, the anaerobiosisinduced cell elongation occurs within a range that is permissive for cell growth.
Our subsequent experiments uncovered the fact that cell elongation was mediated by $\mathrm{NO}$, produced consistently as a spontaneous intermediate of anaerobic respiration [16,17]. Our previous work [6] and a work by Cork and Poole using E. coli as a test organism [47] indicated that NIR activity was necessary to produce NO under anaerobic conditions. Consistent with this
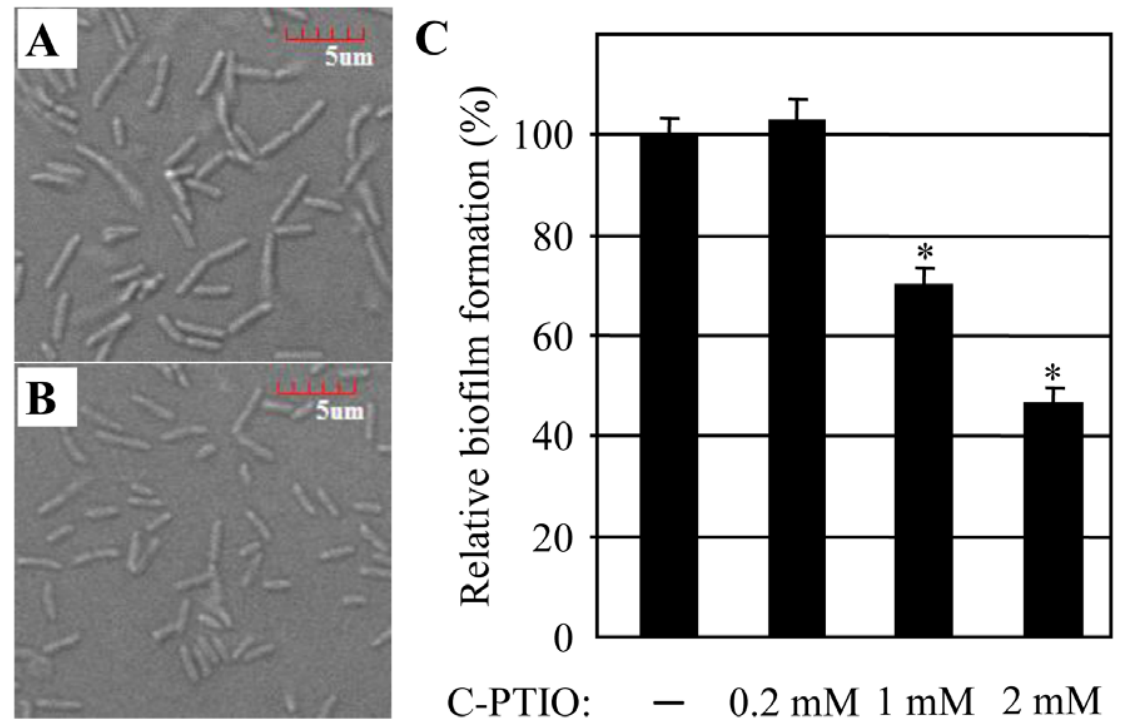

Figure 7. Effects of exogenously amended carboxy-PTIO on cell elongation and anaerobic biofilm formation in PAO1. DIC images of PAO1 grown without (A) or with (B) $2 \mathrm{mM}$ carboxy-PTIO. Cells were grown in LB containing $0.4 \% \mathrm{NO}_{3}{ }^{-}$under the anaerobic condition. Images were acquired and processed as described in Fig. 1 and 5. (C) The effect of carboxy-PTIO on the anaerobic biofilm formation. PAO1 was grown in the absence or presence of increasing concentrations of carboxy-PTIO for 18 hours and biofilm formed in each culture was stained with CV. ${ }^{*} \mathrm{p}<0.001$ vs. biofilms formed in the presence of $2 \mathrm{mM}$ or $1 \mathrm{mM}$ carboxy-PTIO.

doi:10.1371/journal.pone.0016105.g007 
A

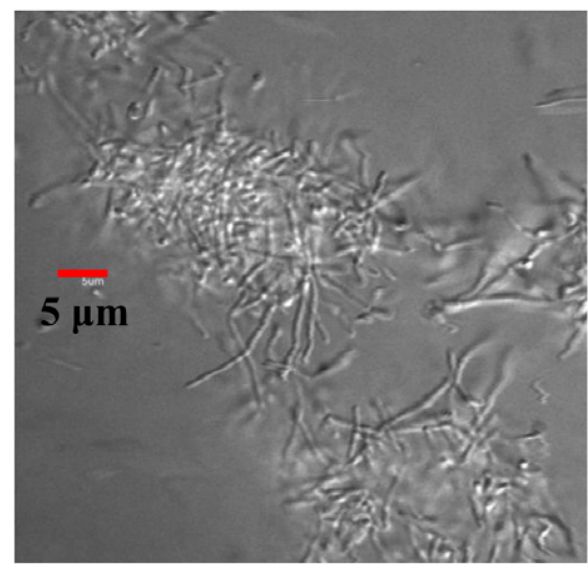

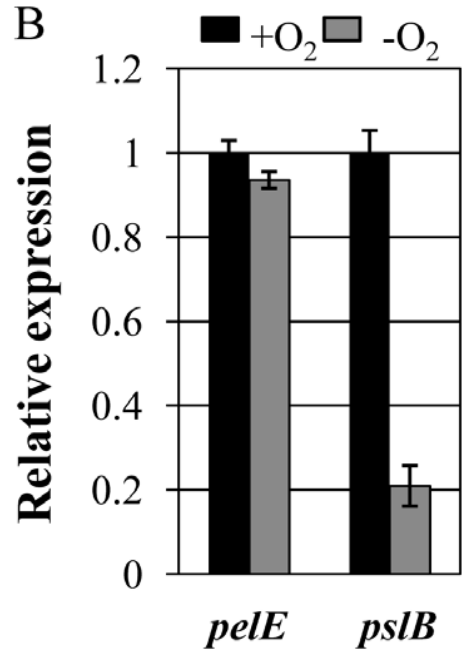

Figure 8. Bacterial clump formation during anaerobic growth and $q R T-P C R$ analysis of genes involved in polysaccharide biosynthesis. (A) A DIC image of clumps observed in a planktonic anaerobic culture of PAO1. A scale bar of $5 \mu \mathrm{m}$ is shown. (B) qRT-PCR was conducted on CDNA synthesized from $2 \mu \mathrm{g}$ total RNA extracted from PAO1 grown either aerobically (black bars) or anaerobically (gray bars). Assay conditions were identical as described in Fig. 4. Three independent experiments were performed and values of mean \pm SEM are displayed in each bar.

doi:10.1371/journal.pone.0016105.g008

finding, the $\Delta$ nir $S$ mutant that was devoid of NIR activity was not elongated under $\mathrm{NO}_{3}{ }^{-}$respiration conditions (Fig. 5). These findings were further proven by the observation that NO-triggered cell elongation was suppressed by the addition of membranepenetrable carboxy-PTIO (Fig. 7).

During airway infection, $P$. aeruginosa encounters significant level of neutrophils infiltrated into the airway mucus. Along with macrophages and airway epithelial cells, neutrophils produce NO as an important defense molecule [48]. Because our results suggest that elongated cells form more robust biofilm, an interesting hypothesis would be whether $P$. aeruginosa responds to host-derived
NO during the infectious process in order to change its cell shape. To test this idea, we have attempted to see the effect of exogenously added $\mathrm{NO}$ via acidified $\mathrm{NO}_{2}^{-}$[26] on the cell shape change in PAOl under aerobic growth condition, but no morphological change in response to NO was observed (data not shown). This may suggest that NO-triggered cell elongation only occurs under anaerobic respiration condition using endogenously produced metabolic NO. More experiments are necessary to precisely determine the effect of $\mathrm{NO}$ on the bacterial cell shape change.

Our results also demonstrated that the elongated cells are inclined to form highly cohesive clumps, which we believe

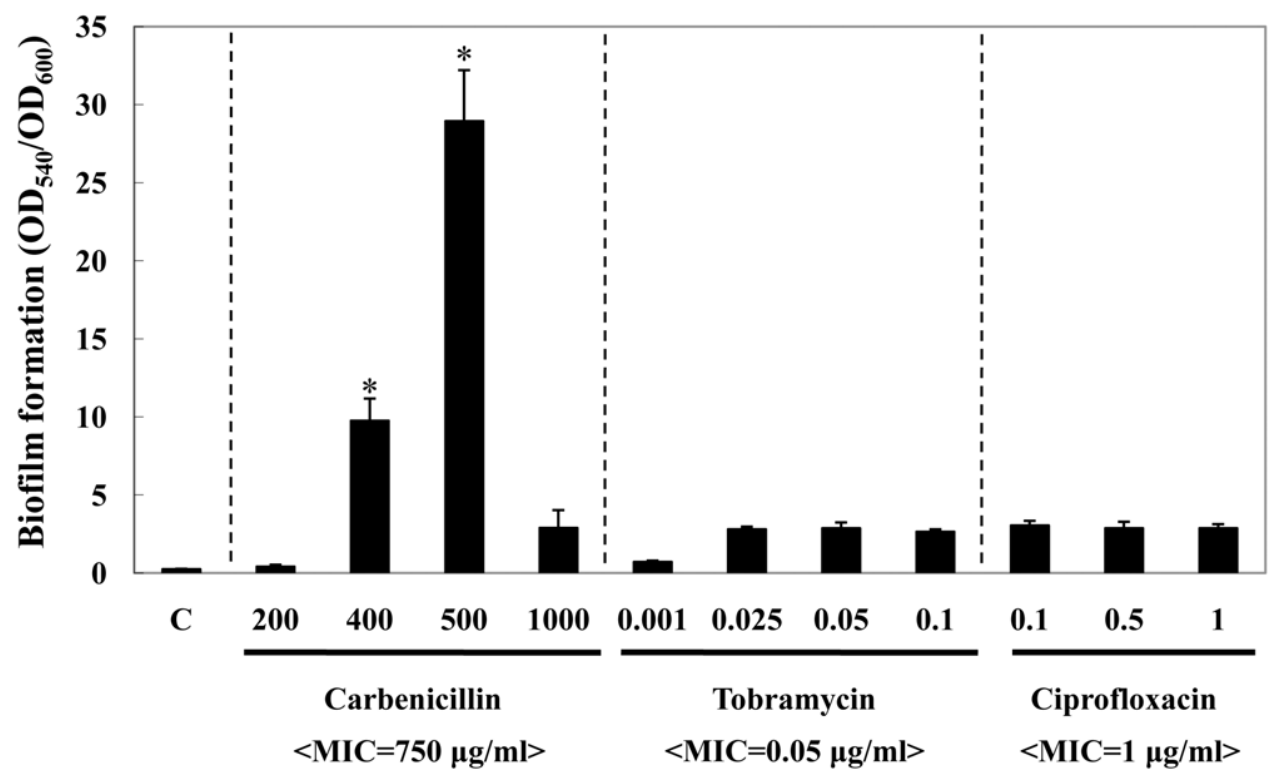

Figure 9. Effects of carbenicillin-induced cell elongation on the biofilm formation in PAO1. Quantification of CV staining of PAO1 biofilms grown with increasing concentrations of carbenicillin, tobramycin or ciprofloxacin (indicated at the bottom). PAO1 was inoculated in antibioticcontaining LB media placed in 96-well plates and grown for $18 \mathrm{hrs}$ aerobically. C: LB only control. ${ }^{*} \mathrm{p}<0.001$ vs. biofilms formed by PAO1 in the presence of tobramycin or ciprofloxacin.

doi:10.1371/journal.pone.0016105.g009 
accounts for the robust biofilm formation under anaerobic condition (Fig. 8). Because clump formation was not observed in non-elongated mutant strains ( $\Delta$ nir $S$ mutant) and aerobically grown $P$. aeruginosa, this finding suggests that anaerobiosis-induced cell elongation likely caused changes in membrane properties that result in the clump formation. Potential questions to be addressed in the future include; (i) how different the cell wall composition of elongated cells is from rod-shaped $P$. aeruginosa and (ii) how the endogenously produced $\mathrm{NO}$ can signal a mechanism by which cells undergo elongation.

The discovery of anaerobiosis-induced morphological change inspired the present study to test its effect on biofilm formation. Since (i) cell-to-cell contact, which is an important determinant for biofilm formation, can be facilitated by an enlarged cell surface and (ii) highly cohesive autoaggregates were only detected in elongated cells, it was hypothesized that the robust anaerobic biofilm formation might result from the elongated cell shape. To address this important question, the elongation-defective mutant(s) were subjected to isolation. However, a genome-wide mutant library screen to isolate such mutants was not feasible, due to the lack of an efficient assay system that would allow us to isolate the defective mutants. Alternatively, the effect of the disruption of genes involved in the anaerobic respiration pathway on the elongation phenotype was examined since cell elongation occurred as a consequence of anaerobic respiration in wild type PAOl (Fig. 1). The results described in Fig. 5 demonstrated that the $\Delta$ nir $S$ mutant remained rod-shaped, while the $\Delta$ nar $G$ mutant was elongated as PAOl under anaerobic growth. This finding provided us with an opportunity to compare the biofilm forming capability of the mutants that were in marked contrast to each other in their cell morphology.

NIR was also reported to be required for the type III secretion system and virulence towards human monocyte cell line THP-1 and Caenorhabditis elegans even in conditions where oxygen is present $[7,49]$. This suggests that NIR is likely important in $P$. aeruginosa pathogenesis irrespective of the environmental oxygen concentration. Results presented in the current study, however, clearly demonstrated the role of NIR in anaerobiosis-specific

\section{References}

1. Costerton JW, Stewart PS, Greenberg EP (1999) Bacterial biofilms: a common cause of persistent infections. Science 284: 1318-1322.

2. Hassett DJ, Elkins JG, Ma JF, McDermott TR (1999) Pseudomonas aeruginosa biofilm sensitivity to biocides: use of hydrogen peroxide as model antimicrobial agent for examining resistance mechanisms. Methods Enzymol 310: 599-608.

3. Stewart PS, Costerton JW (2001) Antibiotic resistance of bacteria in biofilms. Lancet 358: 135-138.

4. Teitzel GM, Parsek MR (2003) Heavy metal resistance of biofilm and planktonic Pseudomonas aeruginosa. Appl Environ Microbiol 69: 2313-2320.

5. Jesaitis AJ, Franklin MJ, Berglund D, Sasaki M, Lord CI, et al. (2003) Compromised host defense on Pseudomonas aeruginosa biofilms: characterization of neutrophil and biofilm interactions. J Immunol 171: 4329-4339.

6. Yoon SS, Karabulut AC, Lipscomb JD, Hennigan RF, Lymar SV, et al. (2007) Two-pronged survival strategy for the major cystic fibrosis pathogen, Pseudomonas aeruginosa, lacking the capacity to degrade nitric oxide during anaerobic respiration. EMBO J 26: 3662-3672.

7. Van Alst NE, Wellington M, Clark VL, Haidaris CG, Iglewski BH (2009) Nitrite reductase NirS is required for type III secretion system expression and virulence in the human monocyte cell line THP-1 by Pseudomonas aeruginosa. Infect Immun 77: 4446-4454.

8. Worlitzsch D, Tarran R, Ulrich M, Schwab U, Cekici A, et al. (2002) Effects of reduced mucus oxygen concentration in airway Pseudomonas infections of cystic fibrosis patients. J Clin Invest 109: 317-325.

9. Ojoo JC, Mulrennan SA, Kastelik JA, Morice AH, Redington AE (2005) Exhaled breath condensate $\mathrm{pH}$ and exhaled nitric oxide in allergic asthma and in cystic fibrosis. Thorax 60: 22-26.

10. Jones KL, Hegab AH, Hillman BC, Simpson KL, Jinkins PA, et al. (2000) Elevation of nitrotyrosine and nitrate concentrations in cystic fibrosis sputum. Pediatr Pulmonol 30: 79-85.

11. Hill D, Rose B, Pajkos A, Robinson M, Bye P, et al. (2005) Antibiotic susceptabilities of Pseudomonas aeruginosa isolates derived from patients with condition. Our conclusion that enhanced biofilm formation occurred under anaerobic condition was due, at least in part, to the NIR-mediated cell elongation and was based on the following results; (i) the non-elongated $\Delta$ nir $S$ mutant did not form biofilm under $\mathrm{NO}_{3}{ }^{-}$respiration conditions (Fig. 6), (ii) the $\Delta$ narG mutant grown by $\mathrm{NO}_{2}{ }^{-}$respiration was highly elongated and formed very robust biofilm (Fig. 6), and (iii) biofilm formation was decreased by the addition of carboxy-PTIO that inhibited cell elongation (Fig. 7).

In summary, this report provides initial insights into the cell shape-dependent biofilm-forming characteristics of $P$. aeruginosa. Anaerobic biofilm formation that represents a persistent bacterial survival mechanism inside the patient airway requires the activity of NIR. Therefore, it is suggested that this key player could serve as a target, inhibition of which can be beneficial as novel antipseudomonas therapeutic interventions are further developed.

\section{Supporting Information}

Figure S1 Final cell density of anaerobic cultures of three $P$. aeruginosa strains. Bacterial strains were grown for 18 hours in LB $+15 \mathrm{mM} \mathrm{NO}_{3}{ }^{-}$(black bars) or $\mathrm{NO}_{2}{ }^{-}$(gray bars) anaerobically. For a negative control, PAOl was grown in plan LB. ${ }^{*} \mathrm{p}<0.01$ vs. growth with $\mathrm{NO}_{3}{ }^{-}$.

(TIF)

Figure S2 DIC images of anaerobically grown PAOl and FRD1. A scale bar of $5 \mu \mathrm{m}$ is indicated in the top of each panel. (TIF)

Table S1 Primers used for qRT-PCR. (DOCX)

\section{Author Contributions}

Conceived and designed the experiments: SSY MYY KML YP. Performed the experiments: SSY MYY KML YP. Analyzed the data: SSY MYY KML YP. Wrote the paper: SSY.

cystic fibrosis under aerobic, anaerobic, and biofilm conditions. J Clin Microbiol 43: 5085-5090.

12. Filiatrault MJ, Wagner VE, Bushnell D, Haidaris CG, Iglewski BH, et al. (2005) Effect of anaerobiosis and nitrate on gene expression in Pseudomonas aeruginosa. Infect Immun 73: 3764-3772.

13. Hassett DJ, Schweizer HP, Ohman DE (1995) Pseudomonas aeruginosa sodA and sodB mutants defective in manganese- and iron-cofactored superoxide dismutase activity demonstrate the importance of the iron-cofactored form in aerobic metabolism. J Bacteriol 177: 6330-6337.

14. Acosta D, Adelman J, Affolder T, Akimoto T, Albrow MG, et al. (2005) Search for new physics using high-mass tau pairs from $1.96 \mathrm{TeV}$ pp collisions. Phys Rev Lett 95: 131801

15. Acosta D, Adelman J, Affolder T, Akimoto T, Albrow MG, et al. (2006) Measurement of bottom-quark hadron masses in exclusive $\mathrm{J} / \mathrm{psi}$ decays with the CDF detector. Phys Rev Lett 96: 202001.

16. Hoffman LR, Richardson AR, Houston LS, Kulasekara HD, MartensHabbena W, et al. (2010) Nutrient availability as a mechanism for selection of antibiotic tolerant Pseudomonas aeruginosa within the CF airway. PLoS Pathog 6: e1000712.

17. Yoon SS, Hennigan RF, Hilliard GM, Ochsner UA, Parvatiyar K, et al. (2002) Pseudomonas aeruginosa anaerobic respiration in biofilms: relationships to cystic fibrosis pathogenesis. Dev Cell 3: 593-603.

18. O'May CY, Reid DW, Kirov SM (2006) Anaerobic culture conditions favor biofilm-like phenotypes in Pseudomonas aeruginosa isolates from patients with cystic fibrosis. FEMS Immunol Med Microbiol 48: 373-380.

19. Jagger KS, Bahner DR, Warren RL (1983) Protease phenotypes of Pseudomonas aeruginosa isolated from patients with cystic fibrosis. J Clin Microbiol 17: 55-59.

20. Hoffman LR, Kulasekara HD, Emerson J, Houston LS, Burns JL, et al. (2009) Pseudomonas aeruginosa lasR mutants are associated with cystic fibrosis lung disease progression. J Cyst Fibros 8: 66-70. 
21. Hassett DJ, Cuppoletti J, Trapnell B, Lymar SV, Rowe JJ, et al. (2002) Anaerobic metabolism and quorum sensing by Pseudomonas aeruginosa biofilms in chronically infected cystic fibrosis airways: rethinking antibiotic treatment strategies and drug targets. Adv Drug Deliv Rev 54: 1425-1443.

22. Mah TF, Pitts B, Pellock B, Walker GC, Stewart PS, et al. (2003) A genetic basis for Pseudomonas aeruginosa biofilm antibiotic resistance. Nature 426: 306-310.

23. Hall-Stoodley L, Stoodley P (2002) Developmental regulation of microbial biofilms. Curr Opin Biotechnol 13: 228-233.

24. O'Toole GA, Kolter R (1998) Flagellar and twitching motility are necessary for Pseudomonas aeruginosa biofilm development. Mol Microbiol 30: 295-304.

25. Ryder C, Byrd M, Wozniak DJ (2007) Role of polysaccharides in Pseudomonas aeruginosa biofilm development. Curr Opin Microbiol 10: 644-648.

26. Yoon SS, Coakley R, Lau GW, Lymar SV, Gaston B, et al. (2006) Anaerobic killing of mucoid Pseudomonas aeruginosa by acidified nitrite derivatives under cystic fibrosis airway conditions. J Clin Invest 116: 436-446.

27. Wong KK, Poole K, Gotoh N, Hancock RE (1997) Influence of OprM expression on multiple antibiotic resistance in Pseudomonas aeruginosa. Antimicrob Agents Chemother 41: 2009-2012.

28. Trunk K, Benkert B, Quack N, Munch R, Scheer M, et al. (2010) Anaerobic adaptation in Pseudomonas aeruginosa: definition of the Anr and Dnr regulons. Environ Microbiol 12: 1719-1733.

29. Benkert B, Ouack N, Schreiber K, Jaensch L, Jahn D, et al. (2008) Nitrateresponsive NarX-NarL represses arginine-mediated induction of the Pseudomonas aeruginosa arginine fermentation arcDABC operon. Microbiology 154: 3053-3060.

30. Goehring NW, Beckwith J (2005) Diverse paths to midcell: assembly of the bacterial cell division machinery. Curr Biol 15: R514-526.

31. Mougous JD, Cuff ME, Raunser S, Shen A, Zhou M, et al. (2006) A virulence locus of Pseudomonas aeruginosa encodes a protein secretion apparatus. Science 312: $1526-1530$

32. Burton P, Holland IB (1983) Two pathways of division inhibition in UVirradiated E. coli. Mol Gen Genet 190: 128-132.

33. Rico AI, Garcia-Ovalle M, Palacios P, Casanova M, Vicente M (2010) Role of Escherichia coli FtsN protein in the assembly and stability of the cell division ring. Mol Microbiol.

34. Goretski J, Zafiriou OC, Hollocher TC (1990) Steady-state nitric oxide concentrations during denitrification. J Biol Chem 265: 11535-11538.

35. Ma L, Conover M, Lu H, Parsek MR, Bayles K, et al. (2009) Assembly and development of the Pseudomonas aeruginosa biofilm matrix. PLoS Pathog 5: e1000354
36. Irie Y, Starkey M, Edwards AN, Wozniak DJ, Romeo T, et al. (2010) Pseudomonas aeruginosa biofilm matrix polysaccharide $\mathrm{Psl}_{\mathrm{s}}$ is regulated transcriptionally by $\mathrm{RpoS}$ and post-transcriptionally by RsmA. Mol Microbiol 78: $158-172$.

37. Friedman L, Kolter R (2004) Two genetic loci produce distinct carbohydraterich structural components of the Pseudomonas aeruginosa biofilm matrix. J Bacteriol 186: 4457-4465.

38. Werner E, Roe F, Bugnicourt A, Franklin MJ, Heydorn A, et al. (2004) Stratified growth in Pseudomonas aeruginosa biofilms. Appl Environ Microbiol 70: 6188-6196.

39. Rella M, Haas D (1982) Resistance of Pseudomonas aeruginosa PAO to nalidixic acid and low levels of beta-lactam antibiotics: mapping of chromosomal genes. Antimicrob Agents Chemother 22: 242-249.

40. Shearer BG, Papavassiliou J, Legakis NJ (1983) Variation in morphological response of resistant clinical isolates of Pseudomonas aeruginosa to carbenicillin. Eur J Clin Microbiol 2: 148-150.

41. Phair JP, Watanakunakorn C, Bannister T (1969) In vitro susceptibility of Pseudomonas aeruginosa to carbenicillin and the combination of carbenicillin and gentamicin. Appl Microbiol 18: 303-306.

42. Walters MC, 3rd, Roe F, Bugnicourt A, Franklin MJ, Stewart PS (2003) Contributions of antibiotic penetration, oxygen limitation, and low metabolic activity to tolerance of Pseudomonas aeruginosa biofilms to ciprofloxacin and tobramycin. Antimicrob Agents Chemother 47: 317-323.

43. Xu KD, Stewart PS, Xia F, Huang CT, McFeters GA (1998) Spatia physiological heterogeneity in Pseudomonas aeruginosa biofilm is determined by oxygen availability. Appl Environ Microbiol 64: 4035-4039.

44. Steinberger RE, Allen AR, Hansa HG, Holden PA (2002) Elongation correlates with nutrient deprivation in Pseudomonas aeruginosa-unsaturates biofilms. Microb Ecol 43: 416-423.

45. Bhatti AR, DeVoe IW, Ingram JM (1976) Cell division in Pseudomonas aeruginosa: participation of alkaline phosphatase. J Bacteriol 126: 400-409.

46. Rolinson GN (1980) Effect of beta-lactam antibiotics on bacterial cell growth rate. J Gen Microbiol 120: 317-323.

47. Corker H, Poole RK (2003) Nitric oxide formation by Escherichia coli. Dependence on nitrite reductase, the NO-sensing regulator Fnr, and flavohemoglobin Hmp. J Biol Chem 278: 31584-31592.

48. Tripathi P, Kashyap L, Singh V (2007) The role of nitric oxide in inflammatory reactions. FEMS Immunol Med Microbiol 51: 443-452.

49. Van Alst NE, Picardo KF, Iglewski BH, Haidaris CG (2007) Nitrate sensing and metabolism modulate motility, biofilm formation, and virulence in Pseudomonas aeruginosa. Infect Immun 75: 3780-3790. 